\title{
Innervation of the Thymus Gland: A Short Review of Function and Histology
}

Bolaji Babalola

Departmet of Endocrinology Studies, Nigeria.

Corresponding Author : Bolaji Babalola, Departmet of Endocrinology Studies, Nigeria. Email: baloji.babalol@.ac.Ng

Received date: January 25, 2018; Accepted date : February 09, 2018; Published date: February 15, 2018

Citation for this Article : Bolaji Babalola, Innervation of the Thymus Gland: A Short Review of Function and Histology

J. Endocrinology and Disorders. Doi: 10.31579/2640-1045/096

Copyright: (c) 2018 Bolaji Babalola .This is an open-access article distributed under the terms of the Creative Commons Attribution License, which permits unrestricted use, distribution, and reproduction in any medium, provided the original author and source are credited.

\begin{abstract}
The thymus, a primary lymphoid organ and the initial site for development of $\mathrm{T}$ cell immunological function, is morphologically similar across species. It is actually an epithelial organ in which its epithelial cells provide a framework containing $T$ cells as well as smaller numbers of other lymphoid cells. A symbiotic interaction exists between the thymic microinvironment and developing $T$ cells, and the specificity of $T$ cell release into the systemic circulation is under thymic control. The thymic cortex in a young animal is heavily populated by developing $T$ cells along with a smaller proportion of associated epithelial cells. Larger, more mature T cells are found in the medulla where epithelial and other cell types are more abundant. Understanding normal morphological features of the thymus and their perturbations provides a cornerstone to assessing immune system function.
\end{abstract}

\section{Keywords}

T-cells, epithelial cells, Epithelial free areas

\section{Introduction}

The rodent thymus develops from the endoderm of the 3rd and 4th pharangeal pouches and surrounding mesenchyme. (Dijkstra and Sminia, 1990) The pharangeal pouch connects with the pharynx via the thymopharangeal duct, remnants of which may be incorporated into the developing thymus giving rise to epithelial cystic structures (Figures 1 and 2). As development progresses, the thymus along with the thyroid and parathyroid, sharing the same pharangeal pouch origin, migrate caudally. They separate around day 15 when the thymus migrates into the thorax. Embryonic thymic remnants can give rise to ectopic thymic tissue in the neckthyroid and parathyroid glands (Suster and Rosai, 1992). Once migration is complete the epithelial cells organize into a loose meshwork separated by the developing vasculature. Following the rapid population with lymphocyte precursors from developing hematopoetic tissues (gestational day 1112 in the mouse), the thymus becomes a lymphoepithelial organ. Because of their common pharyngeal pouch origin, ectopic thyroid and parathyroid can occasionally be found in the thymus.

The thymus is the first of the lymphoid organs to be formed and grows considerably immediately after birth in response to postnatal antigen stimulation and the demand for large numbers of mature $\mathrm{T}$ cells. Genetic factors also influence the age of onset, rate and magnitude of thymus dependant immunological function. In rats and mice, the thymus reaches maximal size by sexual maturity and then gradually involutes.

\section{Fixation and Processing of the Thymus}

Thymic weights are usually measured prior to fixation and following removal of adjacent fat and connective tissue. The thymus of aged, immunosuppressed, or immunodefficient animals may be difficult to locate. In this case, adipose and connective tissues from the anterior mediastinum containing thymic tissue should be collected and fixed without weighing (Kuper et al., 1995).

In routine studies, the thymus is normally fixed in $10 \%$ buffered formalin. The majority of thymic T cells can be shown to express CD3 on formalin fixed, paraffin-embedded tissue.
Similarly, B cells can be demonstrated in formalin fixed tissue with antibodies to CD45R. However, if specific phenotyping of $\mathrm{T}$ cells is required, use of antigen retrieval methods and use of frozen sections may be required (Ward et al., 2006). Some authors prefer that the tissue should be snap-frozen, since phenotyping involves the use of antibodies against cell surface antigens such as CD4 and CD8, which are present only in small amounts and which are lost with conventional fixation (Schuurman et al., 1994). Ethanol fixation is preferred for the demonstration of keratin expression. Special fixation methods used for various procedures in immunotoxicity studies are discussed by Kuper et al. (1995).

\section{Histology}

Of the various lymphoid tissues, the thymus is histologically most consistent across species (Haley, 2003). It is unique among the lymphoid organs in being an epithelial organ. The epithelial cells form an open framework containing predominantly $\mathrm{T}$ lymphocytes, smaller populations of B lymphocytes and plasma cells and scattered populations of other cells such as neuroendocrine cells. It is divided into a morphologically distinct cortex and medulla separated by a vascular corticomedullary zone.

\section{Epithelial Stroma}

The bulk of the supporting framework in the thymus is composed of the network of epithelial-reticular cells (Banks, 1993). Epithelial cells in the subcapsular region of the thymus form a layer 1 or 2 cells deep. In the outer cortex and ensheathing blood vessels, epithelial cells are thin and sheet-like, but elsewhere they assume a stellate appearance.

\section{Epithelium-Free Areas (or "Holes")}

These areas contain occasional phagocytic macrophages and abundant lymphocytes, (predominantly $\mathrm{CD} 4+/ \mathrm{CD} 8+$ ) with a high rate of proliferation. They are thought to offer a separate intrathymic pathway for T-lymphocytes, whereby immature lymphocytes can move between the cortex, corticomedullary zone and medulla without coming into contact with the stromal elements concerned with selection. 


\section{Genetically Modified Animals}

A symbiotic interaction exists between the thymic microenvironment and developing $\mathrm{T}$ cells. Various mouse models have been developed to demonstrate the role of thymic microenvironment in positive and negative selection of $\mathrm{T}$ cells and the potential influence of $\mathrm{T}$ cells on the development of thymic microenvironments.

\section{SCID Mouse}

Severe Combined Immunodefficiency Syndrome (SCID) is a genetic disorder characterized by failure of $\mathrm{B}$ and $\mathrm{T}$ lymphocyte differentiation. An important aspect of $\mathrm{T}$ lymphocyte differentiation requires rearrangement and expression of genes encoding $\mathrm{T}$ lymphocyte antigen-specific receptors (and B lymphocyte surface immunoglobulin receptors). Failure to properly complete these gene rearrangement events results in the elimination of lymphocyte precursors and near absence of mature, functional $\mathrm{T}$ and $\mathrm{B}$ lymphocytes. In mice the enzyme DNA-dependent protein kinase (DNA-PK) is required for gene rearrangement. Lack of this enzyme occurs as a spontaneous autosomal recessive mutation in C.B-17 BALB/c mice. Animals homozygous for the SCID mutation are severely deficient in functional $\mathrm{B}$ and $\mathrm{T}$ lymphocytes.

\section{References}

1. Henbleim AC. Radium treatment of enlarged thymus gland in infants. Am J Roentgenol (1920) 7:191-195

2. Gowans JL, Gesner BM, McGregor DD. The immunological activity of lymphocytes. In: Wolstenholme GEW, O'Connor M, editors. , editors. Biological Activity of the Leucocyte. (Vol. 10), London: Ciba Foundation Study Group; (1961). p. 32-44

3. MacLean LD, Zak SJ, Varco RL, Good RA. The role of the thymus in antibody production: an experimental study of the immune response in thymectomized rabbits. Transplant Bull (1956) 4:21-2

4. Wolstenholme GEW, O'Connor M, editors., editors. Cellular Aspects of Immunity. London: Ciba Foundation Symposium; (1960). 495 p.
5. Medawar PB. Discussion after Miller JFAP and Osoba D. Role of the thymus in the origin of immunological competence. In: Wolstenholme GEW, Knight J, editors. , editors. The Immunologically Competent Cell: Its Nature and Origin. (Vol. 16), London: Ciba Foundation Study Group; (1963). 70 p.

6. Gross L. Pathogenic properties and "vertical" transmission of the mouse leukemia agent. Proc Soc Exp Biol Med (1951) 78:342810.3181/00379727-78-19068

7. Miller JFAP. Role of the thymus in murine leukaemia. Nature (1959) 183:1069.10.1038/1831069a0

8. Miller JFAP. Fate of subcutaneous thymus grafts in thymectomized mice inoculated with leukaemic filtrates. Nature (1959) 184:1809_ 1010.1038/1841809a0

9. Miller JFAP. Recovery of leukaemogenic agent from non-leukaemic tissues of thymectomized mice. Nature (1960) 187:703.10.1038/187703a0

10. Miller JFAP. Analysis of the thymus influence in leukaemogenesis. Nature (1961) 191:248-910.1038/191248a0

11. Miller JFAP. Immunological function of the thymus. Lancet (1961) 2:748-910.1016/S0140-6736(61)90693-6

12. Miller JFAP. Effect of neonatal thymectomy on the immunological responsiveness of the mouse. Proc Roy Soc Lond (1962) 156B:4152810.1098/rspb.1962.0048

13. Gowans JL, McGregor DD, Cowen DM, Ford CE. Initiation of immune responses by small lymphocytes. Nature (1962) 196:651310.1038/196651a0

14. Miller JFAP. The discovery of thymus function. In: Gallagher RB, Gilder J, Nossal GJV, Salvatore G, editors. , editors. Immunology: The Making of a Modern Science. London: Academic Press; (1995). p. 75-84. 